\title{
A Relação entre Conselho de Administração, Desempenho, Valor e Risco no Mercado Brasileiro de Ações
}

\begin{abstract}
Resumo
Dentre os mecanismos de Governança Corporativa, o Conselho de Administração é citado em estudos acadêmicos como fundamental no desempenho e no valor das empresas em diferentes países. O importante papel na defesa dos direitos dos acionistas, evitando que os gestores utilizem a empresa na defesa dos seus próprios interesses, torna este mecanismo relevante em pesquisas empíricas, ainda mais quando se analisa a sua relação com indicadores financeiros. Neste estudo, o objetivo principal foi de analisar a relação entre este mecanismo e o valor, o desempenho e o risco de empresas brasileiras nos anos de 2012 e 2013, por meio de regressão com dados em painel. Para isso, foi criado um índice de Conselho de Administração a partir de perguntas binárias adaptadas de Silva, Santos e Almeida (2011), para ser usado como variável independente nos modelos econométricos. Foi encontrada relação estatística positiva entre o índice proposto e a variável Volatilidade, contrariando o que era esperado. A pesquisa apontou também relações relevantes entre as variáveis dependentes e as de controle. Entre outros resultados, concluiu-se: pela relação positiva entre o tamanho da empresa e o seu desempenho; relação positiva entre o crescimento das vendas e o valor da empresa, a relação positiva entre as variáveis de risco beta e volatilidade; e o fato de que pertencer aos níveis diferenciados de GC da bolsa reduz a volatilidade das ações da firma.
\end{abstract}

Palavras Chave: Conselho de Administração, Valor, Desempenho, Risco, Índice de Governança Corporativa
José Fernando Martins de Paiva Graduação em Administração e MBA em Finanças pela FAGEN/UFU e Mestrando em Administração na Faculdade de Gestão e Negócios - FAGEN/ Universidade Federal de Uberlândia - UFU. Contato: Campus Santa Mônica, Bloco 5M - sala 109M, Santa Mônica, Uberlândia, MG, CEP.: 38408-100. E-mail: josefernandopaiva@yahoo.com.br

Nelize Aparecida de Oliveira Graduação em Administração no Centro Universitário de Patos de Minas - UNIPAM e Mestranda em Administração na Universidade Federal de Uberlândia Faculdade de Gestão e Negócios. Contato: Campus Santa Mônica, Bloco 5M - sala 109M, Santa Mônica, Uberlândia, MG, CEP.: 38408-100.

E-mail: nelizeoliveira@hotmail.com

\section{Fernanda Maciel Peixoto}

Doutora pela CEPEAD/UFMG e Professora Adjunta na Universidade Federal de Uberlândia (UFU). Contato: Av. João Naves de Ávila, n. 2121, Santa Mônica, Uberlândia, MG, CEP.: 38408-100. E-mail: ffmacielpeixoto@gmail.com 


\section{Introdução}

O desenvolvimento do mercado de capitais impulsionou o crescimento das empresas, na medida em que proporcionou um canal de financiamento para que estas empresas aprimorassem tecnologias e investissem em aumentos de produtividade. Neste processo de crescimento das chamadas "grandes corporações modernas", a partir do Século XX, e com a entrada de novos acionistas controladores, o gestor e o proprietário da empresa se dissociaram cada vez mais, e nesta separação de papéis dentro da empresa foram surgindo conflitos de interesses, em que o gestor relegava ao segundo plano o objetivo de maximização da riqueza do acionista, dando origem ao "conflito de agência clássico" (Silveira, 2002). Berle e Means (1932) já apontavam em seu estudo a dissociação de papéis e os conflitos desta separação entre gestores e acionistas, mostrando a crescente relevância do tema ao longo do desenvolvimento do mercado de capitais.

Este conflito de interesses entre os agentes econômicos levanta a questão de um dos mecanismos de Governança Corporativa (GC), o conselho de administração, frente ao valor, desempenho e risco da empresa no mercado de ações. Ou seja, há dúvidas sobre as atividades desenvolvidas pelo conselho de administração e seus benefícios para os investidores e para a empresa, como o aumento do valor e do desempenho da empresa e a consequente redução da percepção de risco da firma pelo investidor. Neste ponto, aponta-se também a contribuição prática deste trabalho para o mercado, sendo mais uma ferramenta para que o investidor possa avaliar de forma mais contundente o efeito do conselho de administração no valor, desempenho e risco das empresas no mercado de capitais.

Ademais, a diferença de objetivos entre gestores e acionistas também foi apontada em outros trabalhos, entre eles o estudo seminal de Jensen e Meckling (1976), que descreve os custos de agência dentro das empresas. Neste contexto, os mecanismos de incentivo e monitoramento subjacentes à GC proporcionaram formas de redução dos custos de agência, por meio do alinhamento entre os objetivos dos administradores e gestores (Silveira, Barros, \& Famá, 2003).

Entre os mecanismos internos da GC, o conselho de administração desempenha importante papel, monitorando a gestão dos administradores da empresa e buscando a maximização da riqueza dos acionistas. A formação ideal do conselho de administração ainda é objeto de estudos, quanto à sua composição e origem dos membros, da mesma forma que a relação, apesar de disseminada, e ainda não totalmente consensual entre pesquisadores, sobre a influência da estrutura do conselho sobre o valor da empresa (Silveira et al. 2003.; Andrade, Salazar, Calegário, \& Silva, 2009).

Nesse contexto, o objetivo deste estudo é avaliar a relação entre conselhos de administração e o valor/desempenho e risco das empresas. A pergunta de pesquisa a ser respondida é: Qual é o efeito do conselho de administração, no desempenho, valor e risco das empresas listadas na BMF\&FBOVESPA? O tema abordado justifica-se pela crescente importância deste mecanismo de GC, além do que não foram encontrados estudos no Brasil abordando o aspecto "risco" e sua relação com conselho de administração, comparando-se com a quantidade de estudos sobre conselho de administração, desempenho e valor, como a pesquisa de Andrade et al. (2009).

Espera-se que, com este estudo, seja evidenciada a influência positiva do conselho de administração no aumento do valor e do desempenho da empresa, bem como na redução de seu risco, devido ao monitoramento e controle dos conselheiros sobre os gestores, evitando-se assim a expropriação dos acionistas minoritários. Dentre os trabalhos utilizados como referência, alguns servirão como base para esta pesquisa, entre eles os de Andrade et al. (2009), Silva, Santos e Almeida (2011), Peixoto (2012) e Lameira (2012).

No que tange ao método da pesquisa, este artigo utilizou regressão em painel, com dados coletados na base Economática, e nos sites das empresas listadas na BM\&FBOVESPA, exceto financeiras, seguradoras e de fundos, por suas particularidades, nos anos de 2012 e 2013. Sobre as variáveis referentes ao Conselho, elas foram coletadas no site da CVM - Comissão de Valores Mobiliários (CVM), e nos Informativos Anuais publicados pelas empresas ao fim dos exercícios sociais. 
Após as regressões, o índice de conselho proposto apresentou relação positiva com a volatilidade, contrariando a literatura. Também foram encontradas relações relevantes entre algumas variáveis dependentes e de controle. Como exemplo, cita-se a relação positiva entre o tamanho da empresa e o desempenho, a relação positiva entre a volatilidade e o beta (sendo estas duas variáveis associadas ao risco e um dos diferenciais desta pesquisa) e o fato de que pertencer aos níveis diferenciados de GC reduz a volatilidade das ações da empresa.

Após esta introdução, apresenta-se o Referencial Teórico, com a literatura nacional e internacional sobre os temas abordados. Na sequência, a metodologia usada, a análise de resultados e as conclusões finais sobre este estudo. Por último, as referências utilizadas no artigo.

\section{Referencial Teórico}

Silveira (2002, p. 1) define a Governança Corporativa (GC) como um "conjunto de mecanismos internos e externos que visam harmonizar a relação entre gestores e acionistas, dada a separação entre poder e propriedade". Assim, pode-se dizer que a GC envolve o controle e o monitoramento dos gestores e desenvolve-se tendo como propósito principal o alinhamento dos interesses dos gestores aos dos acionistas, na busca pela maximização do retorno sobre o investimento. Shleifer e Vishny (1997) apontaram em seu estudo, que a GC fornece garantias de que o valor investido em empresas será devolvido aos investidores, acrescido do retorno pelo investimento.

Shleifer e Vishny (1997) também pesquisaram em alguns países do mundo a importância da GC enquanto garantidor do retorno do investimento a investidores, e a preocupação quanto à expropriação por parte de gestores. Neste estudo, os estágios de desenvolvimento da GC são avaliados nos seguintes países: Itália, Rússia, Alemanha, Reino Unido, Estados Unidos e Japão.

Antes de o termo "Governança Corporativa" existir como tal na literatura, estudos já analisavam a relação entre gestores e acionistas controladores, como os estudos de Jensen e Meckling (1976), e antes deles, o de Berle e Means (1932). Os primeiros autores apontaram em seu estudo o conflito de interesses entre os acionistas e os gestores, que os representavam, e a defesa dos interesses dos acionistas dentro da empresa. Segundo Berle e Means (1932), a dissociação entre propriedade e controle das empresas foi a origem do denominado custo de agência, apesar de, na época, eles ainda não utilizarem o termo "custo de agência" no contexto norte-americano.

Nesse contexto, é importante situar a Economia dos Custos de Transação. A ECT preocupa-se com as ações oportunistas no mundo corporativo. Rodrigues (2003, p.8) enfatiza que "a economia dos custos de transação consiste no estudo dos mecanismos adotados pelas empresas para minimizar os efeitos decorrentes dos riscos envolvidos na rede de contratos estabelecidos entre os diversos agentes". Nesse sentido em conformidade com a Teoria da Agência, mecanismos de GC, como o Conselho de Administração poderiam, portanto, colaborar para a ECT.

Os custos de agência apontados por Berle e Means (1932) estão relacionados com os custos de transação conceituados por Coase (1937). Segundo este autor, estes custos abrangem os custos entre as transações e contratos dos agentes econômicos envolvidos com a empresa, como acionistas, agentes, funcionários, fornecedores, etc.

Ao abordar a Economia dos Custos de Transação (ECT), é importante resgatar os estudos de Alchian e Demsetz (1972) e Williamson (1985). Peixoto (2012) aponta em sua pesquisa que os primeiros autores, Alchian e Demsetz (1972), identificaram o "direito de propriedade" em que as firmas mantêm um contrato com os agentes, e levantaram a impossibilidade de se elaborar contratos completos entre os agentes que não possam ser violados. Por sua vez, Williamson (1985) pesquisou os custos de transação após o fechamento dos contratos, ou seja, o custo para manter estes contratos vigentes. Desta forma, pode 
se inferir que estes autores avaliaram em seus estudos o impacto financeiro do cumprimento dos contratos firmados para a empresa e, consequentemente, para os acionistas. Um dos mecanismos de GC, o conselho de administração, pode ser uma ferramenta importante para a redução destes custos de transação.

Retornando o foco para os estudos sobre governança, há vários trabalhos sobre o efeito da GC no desempenho das empresas, alguns deles de cunho teórico e outros mais empíricos, envolvendo estudos econométricos. Entre os primeiros, o estudo de Lipton e Lorsch (1992, p.4) descreve a importância da GC nas empresas dos EUA, especialmente para aquelas que não conseguem atingir o desempenho desejado, da seguinte forma: "para empresas com baixa performance devido a gestão pobre ou persistindo em uma estratégia ineficiente, a boa governança corporativa é a válvula mais segura para prover os meios para lidar com este problema e melhorar a performance".

Nessa pesquisa, Lipton e Lorsch (1992) analisam o papel, a importância e possíveis alterações na configuração dos conselhos de administração. Entre elas, os autores sugerem que a defesa dos interesses dos acionistas e da empresa pode ser alcançada com números menores de membros no conselho, permitindo a participação de todos os conselheiros nos debates sobre a empresa; reuniões mais frequentes, pelo menos a cada dois meses, e recompensas de acordo com os desafios assumidos por cada diretor da empresa e resultados alcançados.

Lipton e Lorsch (1992) também citam a dificuldade da separação de papéis entre o CEO da empresa e o chairman, ou presidente do conselho, algo mais comum naquela época às empresas europeias e, não, em norte-americanas.

A seguir, serão comentados alguns estudos sobre governança corporativa, nos EUA, Ásia e Europa, e na sequência artigos relacionando GC às outras variáveis em estudo neste artigo no Brasil.

O estudo teórico de Hermalin e Weisbach (2001) faz um levantamento bibliográfico sobre temas relacionados aos conselhos de administração, entre eles: o tamanho do conselho, sua composição, as características do conselho e sua independência. Outros pontos levantados pelo artigo são a rotatividade do CEO nas empresas, e a disputa entre o CEO e os conselheiros de administração por seus interesses. Entre outras conclusões, o levantamento não permitiu aos autores apontarem políticas para adequação do tamanho e da composição do conselho, tendo como objetivo sua maior independência, e citam o problema de conflitos entre diretores do conselho e a influência do CEO sobre eles.

Estudos relacionados ao tema "conselho de administração" foram publicados sobre diferentes abordagens e em diferentes países. Analisaram, entre outras variáveis, o efeito da presença de conselheiras na performance das empresas nos EUA (Carter, Simkins, \& Simpson, 2013) e na Alemanha (Joecks, Pull, \& Vetter, 2013); o número de membros no conselho de administração nos EUA (Coles, Daniel \& Naveen, 2008); a presença de membros externos nos conselhos de administração de empresas indianas (Kumar \& Singh, 2012); e a presença de funcionários da empresa nos conselhos das empresas na Alemanha (Fauver \& Fuerst, 2006), relacionando estas variáveis especialmente com o valor e o desempenho da empresa.

Há também trabalhos que mensuraram a relação destas variáveis por meio da construção de índices de GC. Neste sentido, Beiner, Drobetz, Schimid e Zimmermann (2004) construíram um índice para analisar a relação entre a GC e o valor de empresas listadas na bolsa de valores suíça. Para isso, os autores usaram o tamanho do conselho e a presença de conselheiros externos, entre outras variáveis, para construir o índice. Concluíram pela relação positiva entre GC e desempenho.

Na Alemanha, Fauver e Fuerst (2006) analisaram se a presença de funcionários nos conselhos de administração aumentaria o valor das empresas alemãs, e se a influência desses funcionários, defendendo interesses dos trabalhadores, indiretamente protegeria os interesses de acionistas minoritários. Naquele país, os conselhos são divididos em dois grupos (de supervisão e de gerenciamento), sendo o primeiro o responsável por atividades inerentes ao conselho de administração, da forma como é adotada nos EUA. O segundo grupo seria o responsável pela gestão operacional da empresa. Os autores concluíram que até 
certo ponto, a presença de trabalhadores influencia positivamente no valor da firma, mas, após esse ponto, pode haver problemas de agência, sendo os funcionários-conselheiros os próprios causadores de expropriação (relação entre funcionários e desempenho em forma de U invertido).

$\mathrm{Na}$ Ásia, Shakir (2008) analisou a relação entre a composição do conselho de administração e a performance de empresas da Bolsa de Valores de Kuala Lumpur, na Malásia. Os resultados finais do artigo não foram conclusivos pelos benefícios da participação de conselheiros externos, mas apontaram que um número menor de membros no conselho seria melhor para diminuir a assimetria de informações e permitir uma liderança centralizada do conselho.

Em outro artigo, Velnampy (2013) pesquisou a performance de empresas no mercado de capitais, do Siri Lanka, com uma amostra de 28 empresas industriais no período de 2007 a 2011. Por meio de regressão múltipla, o estudo buscou relacionar as variáveis de estrutura de conselho, presença de comitês executivos, frequência de reuniões dos conselheiros, independência dos conselheiros e membros internos e externos, com a performance da empresa, utilizando o ROA e o ROE. As conclusões do autor foram pela não significância entre a performance da empresa e as medidas de conselho usadas como variáveis independentes.

Nos EUA, o estudo da performance e do valor das empresas e sua possível relação com o conselho de administração também se tornou comum, principalmente após a promulgação da Lei Sarbanes-Oxley (SOX), em 2002, quando, após escândalos de corrupção e má gestão de empresas, houve a elaboração e implementação de leis mais rígidas para os gestores de empresas norte-americanas. Como exemplo, aponta-se o estudo de Bhagat e Bolton (2009), que analisou a relação da performance de empresas nos EUA com variáveis de GC, antes e após a lei. Entre as conclusões dos autores, não foi encontrada associação significativa entre a independência do conselho e a performance de empresas no que eles chamaram de período pré-crise até 2002, e relação positiva após 2002, denominado "período pós-crise".

No Brasil, algumas pesquisas também encontraram relações entre fatores ligados ao conselho de administração e o desempenho, valor e risco das empresas. Na sequência, serão abordados alguns destes estudos.

Silveira et al. (2003), analisando mecanismos de governança, dentre eles, o conselho de administração, levaram em consideração três variáveis: separação dos cargos de diretor executivo e presidente do conselho (DE), tamanho do Conselho (TOT) e grau de independência do Conselho (Indep). Os resultados dos autores sugerem que, em média, empresas que possuem pessoas distintas ocupando os cargos de diretor executivo e presidente do conselho são mais valorizadas pelo mercado.

Através de regressão múltipla hierárquica, Andrade et al. (2009) investigaram a influência do conselho de administração no valor e desempenho de empresas brasileiras não financeiras no período de 2004 a 2006. Constataram a existência de uma relação positiva entre o número de conselheiros e o valor e desempenho da empresa, e que a composição dos conselhos tem maior relação com o valor da empresa, em comparação ao desempenho.

Silva et al. (2011) verificaram a influência do conselho de administração sobre o endividamento de empresas que aderiram aos níveis diferenciados de GC no ano de 2008, por meio do método dos Mínimos Quadrados Ordinários (MQO). Para este estudo, os autores usaram como proxy do conselho, um questionário com 6 perguntas binárias e objetivas, valendo 1 ponto cada. O questionário utilizado nesta pesquisa é apresentado na Tabela 1. Silva et al. (2011) apontaram que a elaboração deste questionário levou em consideração as melhores práticas recomendadas pelo IBGC, a CVM, a BM\&FBOVESPA, e os estudos de Carvalhal da Silva e Leal (2006) e Santos e Leal (2007). 
Tabela 1

Perguntas para proxy do Conselho

\begin{tabular}{l}
\hline \multicolumn{1}{c}{ Perguntas para proxy do Conselho } \\
\hline 1 - O presidente do Conselho e o CEO são pessoas diferentes? \\
\hline 2 - A empresa tem comitês de monitoramento, como comitê de remuneração, e/ou nomeação, e/ou auditoria? \\
\hline 3 - O conselho é claramente composto por conselheiros externos, e possivelmente independentes (não ligados aos \\
controladores)? \\
\hline 4 - O conselho possui entre 5 e 9 membros, conforme recomenda o código do IBGC? \\
\hline 5 - Os membros do conselho tem mandato de 1 ano, conforme recomenda o código do IBGC? \\
\hline 6 - A empresa possui Código Fiscal permanente? \\
\hline Fonte: Silva et al. (2011)
\end{tabular}

Os autores encontraram significância positiva apenas com o endividamento de curto prazo, e negativa com o endividamento total e de longo prazo. Concluíram pelo alinhamento do conselho de administração com o interesse do acionista controlador no endividamento, e que a dívida de curto prazo tem potencial para disciplinar os gestores.

Fraga e Silva (2012) pesquisaram a relação entre a diversidade dos membros do conselho de administração e o desempenho da empresa. Usando 71 observações no período entre 2005 a 2009, foram construídos índices de diversidade, com características dos membros do conselho: sexo, idade, escolaridade e educação formal. Por meio de regressão, os autores concluíram pela relação positiva entre escolaridade e desempenho, e negativa entre as áreas de educação formal e desempenho. Por último, apontaram a relação positiva forte entre a presença de mulheres no conselho e o desempenho da empresa.

Gondrige, Clemente e Espejo (2012) analisaram a relação do valor da empresa com o número de membros no conselho de administração (NMembros), a independência (Indep) e o acúmulo de cargo de presidente do conselho e CEO da empresa pela mesma pessoa (CeoPowerful). Para isso, usaram uma amostra de 208 empresas brasileiras, no ano de 2008, pela regressão linear múltipla. O resultado encontrado apontou relação significante positiva entre o número de conselheiros e o valor da empresa, indicando que a presença de conselhos maiores induz à elevação do valor da firma.

Apesar de não tratarem diretamente do conselho de administração, alguns estudos de governança serviram de inspiração para o presente trabalho no momento de seleção das variáveis de controle dos modelos econométricos, dentre eles, pode-se citar: Lameira (2012), Peixoto (2012) e Guimarães, Marques e Peixoto (2014).

Lameira (2012) analisou a relação entre GC e o risco, pela regressão linear e o uso de equações estruturais para uma amostra de empresas brasileiras não financeiras, no período de 2002 a 2006. Para a análise desta relação, o autor elaborou um índice de qualidade da GC, sendo este composto pelas respostas de 20 perguntas binárias. Esperava-se que melhores níveis de GC estivessem associados a menores riscos, o que foi corroborado pela pesquisa.

Por sua vez, Peixoto (2012) e Guimarães et al. (2014) relacionaram mecanismos de GC com as variáveis risco, desempenho e valor de empresas brasileiras.

O trabalho de Peixoto (2012) analisou a relação entre GC e desempenho, valor e risco de empresas brasileiras, no período de 2000 a 2009. Envolveu a elaboração de um índice de qualidade da GC, por meio do método de análise de componentes principais. Em seguida, adotando regressão com dados em painel, verificou-se a relação entre o índice e as variáveis desempenho, valor e risco. Entre outras conclusões do trabalho, não foram encontradas relações significantes entre o desempenho contábil e GC, e entre as medidas de risco e a GC. No entanto, o estudo constatou que há relação positiva entre o valor e GC em momentos de crise econômica. 
O segundo estudo analisou, com dados em painel, uma possível relação entre a estrutura de propriedade e controle com o desempenho, valor e risco de empresas não financeiras no período de 2004 a 2012. Entre outros resultados, o estudo concluiu que as variáveis risco e desempenho não foram afetadas de forma significativa pela concentração acionária, e houve uma relação negativa entre concentração do direito de voto e valor de mercado.

Holtz, Vargas, Macedo e Bortolon (2013) analisaram variáveis contábeis e financeiras que influenciaram na quantidade de membros dos conselhos de administração de 315 empresas listadas na BM\&FBOVESPA, com informações coletadas no formulário de referência de 2012. Os autores concluíram que empresas com maior endividamento e valor de ativos intangíveis possuíam maiores conselhos devido à necessidade de aconselhamento e monitoramento, e também que empresas com maior fluxo de caixa operacional possuíam conselhos menores, justificado pelos autores pela necessidade de reduzir os conflitos pelo excesso de caixa na empresa.

No presente estudo, será elaborado um índice para mensurar as variáveis de Conselho de Administração, conforme metodologias usadas por de Silva et al. (2011) e Lameira (2012), de forma a consolidar em um único indicador as métricas que tornam o Conselho de Administração mais coerente com as recomendações do IBGC.

Diante dos estudos citados, mostra-se a importância do estudo das variáveis risco, desempenho e valor, associadas ao conselho de administração. Não foram encontrados artigos sobre a relação destas variáveis conjuntas com o mecanismo de GC em estudo, no Brasil, ou no exterior, mostrando a relevância desta pesquisa. A seguir, são apresentadas as hipóteses que serão testadas neste estudo:

H1: Há uma relação positiva entre o índice de Conselho de Administração desenvolvido nesta pesquisa com o desempenho e valor das firmas.

H2: Há uma relação negativa entre o índice de Conselho de Administração desenvolvido nesta pesquisa com o risco.

Com este estudo, espera-se, portanto, que haja uma relação positiva entre o conselho de administração, o valor e o desempenho da empresa, mostrando que o conselho de administração tem influência na performance da empresa. Da mesma forma, que também seja encontrada uma associação negativa entre o conselho de administração e o risco para investidores.

\section{Aspectos Metodológicos}

\subsection{Dados, Amostra e Método Utilizado}

O presente estudo pode ser caracterizado como descritivo e quantitativo. A amostra formou um painel desbalanceado de empresas listadas na BM\&FBOVESPA, exceto financeiras, seguradoras e de fundos, compreendendo os anos de 2012 e 2013. Utilizou-se de dados secundários coletados no site da bolsa de valores citada, nos relatórios anuais e sites das empresas, no banco de dados Economática e no site da Comissão de Valores Mobiliários (CVM).

As empresas listadas foram selecionadas com base no filtro de liquidez proposto por Silveira (2002). Consideraram-se como empresas com liquidez significativa as empresas que apresentaram índice de liquidez anual calculado pelo Economática maior que $0,001 \%$ do índice correspondente à empresa com ações mais líquidas no período total investigado, incluindo, necessariamente, o ano de 2013, último ano da coleta de dados. Silveira (2002, p.75) justifica esta opção da seguinte forma: "empresas com liquidez muito baixa possuem uma probabilidade menor de terem suas ações adequadas ao valor de mercado". 
O método econométrico utilizado foi o de regressão com dados em painel, com o uso do software Stata. Inicialmente foi realizado o teste VIF (Variance Inflation Factor) a fim de verificar se alguma das variáveis deveria ser retirada do modelo. O resultado do VIF para todas as variáveis individuais apresentou valor menor que 10, bem como o teste para o conjunto de variáveis do modelo. Dessa forma nenhuma das variáveis precisou ser retirada do modelo.

O teste Breusch-Pagan foi adotado para determinar entre o modelo Pooled ou de efeitos aleatórios, ou seja, se havia homogeneidade entre as unidades cross-section, chegando-se ao resultado de que o Pooled não se adequa a nenhum dos modelos propostos no presente trabalho. Finalmente, o teste de Hausman indicou qual modelo se ajustava melhor, se o de efeitos fixos ou aleatórios. Para os modelos cujas variáveis dependentes são ROA, Q de Tobin e BETA, o modelo de efeitos fixos mostrou-se mais adequado; já para a variável dependente VOLAT. o modelo de efeitos aleatórios se adequou melhor.

A definição das variáveis dependentes, independentes e de controle deste estudo foram embasadas nos estudos de Andrade et al. (2009), Silva et al. (2011), Peixoto (2012), Lameira (2012), e Guimarães et al. (2014), entre outros.

A variável proxy para caracterização do conselho de administração foi desenvolvida seguindo o modelo de Silva et al. (2011), em que os autores usaram 6 (seis) perguntas binárias para a construção da variável, aqui denominada de Índice do Conselho de Administração (ICA). A terceira pergunta do questionário original foi substituída por apresentar possiblidades de respostas subjetivas e questionamentos quanto a sua interpretação. Buscando-se maior isenção e objetividade na coleta dos dados e na análise dos resultados, optou-se pela mudança no questionário. As perguntas estão dispostas na Tabela 2

Com as respostas coletadas, obteve-se um índice para mensuração das variáveis de conselho de administração (ICA), conforme recomendações do IBGC para composição/estrutura dos conselhos. O índice proposto foi a variável independente de teste nos modelos econométricos.

Tabela 2

Perguntas para proxy do conselho

\begin{tabular}{l}
\hline \multicolumn{1}{c}{ Perguntas para proxy do Conselho } \\
\hline 1 - O presidente do Conselho e o CEO são pessoas diferentes? \\
\hline - A empresa tem comitês de monitoramento, como comitê de remuneração, e/ou nomeação, e/ou auditoria? \\
\hline 3 - O conselho possui mais de $20 \%$ do seu quadro formado por membros externos? \\
\hline 4 - O conselho possui entre 5 e 9 membros, conforme recomenda o código do IBGC? \\
\hline 5 - Os membros do conselho tem mandato de 1 ano, conforme recomenda o código do IBGC? \\
\hline 6 - A empresa possui Código Fiscal permanente?
\end{tabular}

Fonte: adaptado de Silva et al. (2011)

As respostas positivas obtidas com o questionário somam um ponto para a empresa, então cada empresa pode atingir no máximo 6 pontos. Em contrapartida, as respostas negativas não adicionam pontos. A pontuação de cada empresa, portanto, foi entre 0 e 6 . 


\subsection{Variáveis Selecionadas para o Estudo}

\subsubsection{Variáveis Dependentes}

\section{Desempenho}

O desempenho da empresa pode ser mensurado de diversas formas, entre elas fazendo-se o uso do ROA (retorno sobre o ativo) utilizado por Carvalhal da Silva e Leal (2006), Guimarães et al. (2014), Silva et al. (2011), Beiner et al. (2004) e Velnampy (2013). Espera-se que a configuração recomendada pelo IBGC para o conselho de administração tenha efeito positivo sobre o desempenho das empresas.

O cálculo do ROA foi feito pela razão entre o lucro líquido e o ativo total da empresa.

\section{Valor}

Uma das proxies para o valor da firma é o Q de Tobin, conforme estudos de Carvalhal da Silva (2004), Carvalhal da Silva e Leal (2006), Guimarães et al. (2014), Peixoto (2012), Shakir (2008), entre outros. Analisando a razão entre o valor de mercado das ações da empresa somado ao seu endividamento, pelo valor do ativo total, como proposto por Chung e Pruitt (1994), espera-se que esta variável também tenha relação positiva com o conselho de administração.

Para mensurar o Q de Tobin, calculou-se a soma do valor de mercado das ações com o endividamento total da empresa, dividido pelo seu ativo total.

\section{Risco}

Para a mensuração do risco, foram escolhidas duas variáveis: o Beta e a Volatilidade. Ambas foram utilizadas no trabalho de Peixoto (2012) e Lameira (2012). Por sua vez, Guimarães et al. (2014) também utilizaram a variável Volatilidade para mensurar o risco das ações. Espera-se que haja uma redução do risco nas empresas que adotarem as recomendações do IBGC quanto ao conselho de administração.

A fórmula para o cálculo das variáveis é o seguinte: para o Beta, faz-se a regressão do retorno mensal do título contra o retorno mensal do Ibovespa, considerando os 60 meses anteriores. E, para a Volatilidade, o cálculo é feito pelo logaritmo natural da razão entre a cotação da ação pela sua cotação do dia anterior.

\subsubsection{Variáveis de Controle}

As variáveis de controle foram as seguintes: a) o logaritmo natural do valor da firma (LNVM); b) o logaritmo do ativo total (LNAT); c) a alavancagem financeira (AF); d) a alavancagem operacional (AO); e) o crescimento das vendas (CRESC_VEND); f) o retorno sobre o patrimônio líquido (ROE); g) o endividamento (ENDIV); h) o logaritmo entre a razão do patrimônio líquido por ação e seu preço (LOGVPAP); i) o volume de negociações com a ação (LIQBOL); e j) a dummy NGOV, referente ao nível de GC que a empresa aderiu (se forem Níveis 2 ou Novo Mercado será igual a 1, caso contrário será 0 ). A fundamentação teórica (estudos) que embasaram a escolha de cada variável foi apresentada na Tabela 3. 
Tabela 3

\section{Relação de Variáveis}

\begin{tabular}{|c|c|c|c|c|}
\hline \multicolumn{5}{|c|}{ Variáveis Dependentes } \\
\hline & Cálculo & Medida de: & Sinal Esperado & Autores \\
\hline ROA & Lucro Líquido/Ativo Total & Desempenho & + & $\begin{array}{l}\text { Carvalhal da Silva e Leal (2006) } \\
\text { Guimarães et al. (2014) } \\
\text { Silva et al. (2011); Beiner et al } \\
\text { (2004); Velnampy (2013) }\end{array}$ \\
\hline $\begin{array}{l}\text { Q DE } \\
\text { TOBIN }\end{array}$ & $\begin{array}{l}\text { É definido como o valor de mercado das } \\
\text { ações, acrescido do valor contábil das } \\
\text { dívidas ou capital de terceiros, dividido } \\
\text { pelo ativo total. }\end{array}$ & Valor & + & $\begin{array}{l}\text { Peixoto (2012); } \\
\text { Shakir (2008); Guimarães et al. } \\
\text { (2014); Fauver e Fuerst (2006); } \\
\text { Beiner et al. (2004) }\end{array}$ \\
\hline BETA & $\begin{array}{l}\text { Regressão do Retorno mensal do título } \\
\text { contra o retorno mensal do Ibovespa, } \\
\text { considerando os } 60 \text { meses anteriores. } \\
\text { Coletado no Economática }\end{array}$ & Risco & - & $\begin{array}{l}\text { Lameira (2007); } \\
\text { Peixoto (2012); } \\
\text { Guimarães et al. (2014); Beiner } \\
\text { et al. (2004) }\end{array}$ \\
\hline VOLAT & $\begin{array}{l}\text { Ln entre cotação de fechamento do período t } \\
\text { e do período t-1. (Economática) }\end{array}$ & Risco & $-/+$ & $\begin{array}{l}\text { Guimarães et al. (2014); } \\
\text { Peixoto (2012) }\end{array}$ \\
\hline \multicolumn{5}{|c|}{ Variáveis de Controle } \\
\hline & Cálculo & Medida de: & Sinal Esperado & Autores \\
\hline LNVM & $\begin{array}{l}\text { Logaritmo do Valor da Firma: indicador } \\
\text { fornecido pela Economática }\end{array}$ & Valor & + & Andrade et al. (2009) \\
\hline LNAT & Logaritmo neperiano do ativo total. & Valor & + & $\begin{array}{l}\text { Guimarães et al. (2014); } \\
\text { Lameira (2012); Andrade et al. } \\
\text { (2009) }\end{array}$ \\
\hline $\mathrm{AF}$ & $A f=\frac{\frac{(L L / P L)}{(L L-r e s f i n)}}{A T}$ & Risco & - & Peixoto (2012); Lameira (2012) \\
\hline $\begin{array}{l}\text { CRESC } \\
\text { VEND }\end{array}$ & $\begin{array}{l}\text { Variação percentual da receita operacional } \\
\text { líquida total de um ano para outro. }\end{array}$ & Desempenho & + & $\begin{array}{l}\text { Peixoto (2012); Guimarães et } \\
\text { al. (2014) }\end{array}$ \\
\hline ROE & $\begin{array}{l}\text { Razão entre o lucro líquido do período e o } \\
\text { valor contábil do patrimônio líquido. }\end{array}$ & Desempenho & + & $\begin{array}{l}\text { Lameira, Júnior, da Silva, da } \\
\text { Mota e Klötzle (2010) } \\
\text { Peixoto (2012); Velnampy } \\
\text { (2013); }\end{array}$ \\
\hline $\mathrm{AO}$ & $A o=\frac{(R L O-C P V)}{(R L O-C P V-D V-D A)}$ & Risco & + & Peixoto (2012); Lameira (2012) \\
\hline ENDIV & Exigível Total/Ativo Total & Risco & - & Andrade et al. (2009) \\
\hline LGOVPAP & $\begin{array}{l}\text { Logaritmo natural do índice valor patrimonial } \\
\text { por ação/preço, que consiste na razão entre } \\
\text { o patrimônio líquido por ação e o seu preço. }\end{array}$ & Valor & + & Peixoto (2012) \\
\hline LIQBOL & Volume relativo de negociações com a ação & Desempenho & + & Peixoto (2012) \\
\hline NGOV & $\begin{array}{l}\text { Dummy } 1 \text { para empresas nos Níveis } 2 \text { e } \\
\text { Novo Mercado, e } 0 \text { para as empresas nos } \\
\text { demais Níveis de Governança Corporativa da } \\
\text { Bovespa e no mercado tradicional. }\end{array}$ & Valor & + & $\begin{array}{l}\text { Holtz et al. (2013); Lameira } \\
\text { (2012) }\end{array}$ \\
\hline
\end{tabular}

Fonte: elaborado pelos autores 
A partir da seleção das variáveis, são apresentados abaixo os modelos econométricos para análise da relação entre conselho de administração com desempenho/valor/risco:

\section{Desempenho:}

$$
\mathbf{R O A}_{\mathrm{it}}=\beta_{0}+\beta_{1} \mathrm{ICA}_{\mathrm{i}, \mathrm{t}}+\beta_{2} \mathrm{LNAT}_{\mathrm{it}}+\beta_{3} \mathrm{ENDIV}_{\mathrm{it}}+\beta_{4} \mathrm{LOGVPAP}_{\mathrm{it}}+\beta_{5} \mathrm{NGOV}_{\mathrm{it}}+\varepsilon_{\mathrm{i}}
$$

Valor:

Q de Tobin it $=\beta_{0}+\beta_{1} \mathrm{ICA}_{\mathrm{i}, \mathrm{t}}+\beta_{2} \mathrm{LNAT}_{\mathrm{it}}+\beta_{3} \mathrm{ENDIV}_{\mathrm{it}}+\beta_{4} \mathrm{AF}_{\mathrm{it}}+\beta_{5} \mathrm{CRESC}_{-} \mathrm{VEND}_{\mathrm{it}}+$ $\beta_{6} \mathrm{ROE}_{\mathrm{i}, \mathrm{t}}+\beta_{7} \mathrm{LIQBOL}_{\mathrm{t}}+\beta_{8} \mathrm{NGOV}_{\mathrm{it}}+\varepsilon_{\mathrm{i}}$

(Modelo 2)

\section{Risco:}

Beta $_{\text {it }}=\beta_{0}+\beta_{1}$ ICA $_{\text {i,t }}+\beta_{2}$ VOLAT $_{i t}+\beta_{3}$ LOGVPAP $_{\text {it }}+\beta_{4}$ LOGVM $_{\text {it }}+\beta_{5} \mathrm{LIQBOL}_{\text {it }}+$
$\beta_{6} \mathrm{AO}_{\mathrm{i}, \mathrm{t}}+\beta_{7} \mathrm{AF}_{\mathrm{t}}+\beta_{8} \mathrm{CRESC}_{-} \mathrm{VEND}_{\mathrm{it}}+\beta_{9} \mathrm{NGOV}_{\mathrm{it}}+\varepsilon_{\mathrm{i}}$

Volat $_{\text {it }}=\beta_{0}+\beta_{1} \mathrm{ICA}_{\mathrm{itt}}+\beta_{2} \mathrm{BETA}_{\mathrm{it}}+\beta_{3} \mathrm{LOGVPAP}_{\mathrm{it}}+\beta_{4} \mathrm{LOGVM}_{\mathrm{it}}+\beta_{5} \mathrm{LIQBOL}_{\mathrm{it}}+$ $\beta_{6} \mathrm{AO}_{\mathrm{i}, \mathrm{t}}+\beta_{7} \mathrm{AF}_{\mathrm{t}}+\beta_{8} \mathrm{CRESC}_{-} \mathrm{VEND}_{\mathrm{it}}+\beta_{9} \mathrm{NGOV}_{\mathrm{it}}+\varepsilon_{\mathrm{i}}$

(Modelo 4)

\section{Análise Dos Resultados}

Neste item será apresentada a estatística descritiva das variáveis investigadas, as correlações entre as variáveis e os resultados das regressões dos modelos estimados, e também os resultados dos testes de diferenças de médias entre as respostas das perguntas do questionário e as variáveis dependentes deste estudo.

\subsection{Análise Descritiva}

O teste de Variance Inflaction Factor (VIF) para cada variável, bem como o VIF médio, indicou que não existem problemas de multicolinearidade (VIF menor que 10). Dessa forma, nenhuma das variáveis precisa ser excluída do modelo. O próximo passo envolveu os testes de diagnóstico dos modelos e a sua estimação, envolvendo a apresentação dos resultados das regressões das variáveis de interesse. Por fim, todos os modelos utilizaram robust para evitar possíveis problemas de multicolinearidade, apesar de não identificados pelo teste VIF, e/ou de autocorreção.

Para a criação do Índice do Conselho de Administração (ICA), foram utilizadas 6 perguntas que receberam valores 0 ou 1 como mencionado na metodologia. Porém, faz-se necessário destacar que a coleta de dados apresentou algumas dificuldades no que tange à disponibilidade das informações necessárias. Dessa forma, as empresas não pontuaram as questões para as quais as respostas não foram encontradas em seus relatórios.

A análise descritiva das variáveis com o número de observações, média, desvio padrão, valores mínimo e máximo é apresentada na Tabela 4. Para tratamento dos outliers encontrados, utilizou-se da técnica de winsorização. 
Tabela 4

\section{Análise descritiva das variáveis}

\begin{tabular}{cccccc}
\hline Variável & Observações & Média & DP & Mínimo & Máximo \\
\hline Q1 & 425 & 0,7835 & 0,4123 & 0 & 1 \\
Q2 & 365 & 0,5233 & 0,5001 & 0 & 1 \\
Q3 & 167 & 0,8292 & 0,3033 & 0 & 1 \\
Q4 & 243 & 0,7407 & 0,4391 & 0 & 1 \\
Q5 & 293 & 0,2935 & 0,4562 & 0 & 1 \\
Q6 & 439 & 0,2756 & 0,4473 & 0 & 1 \\
NGOV & 473 & 0,5455 & 0,4985 & 0 & 1 \\
ROA & 469 & 0.0199 & 0,0686 & $-0,1200$ & 0,1200 \\
ICA & 459 & 2,3072 & 1,4062 & 0 & 6 \\
LNAT & 469 & 14,8216 & 1,6509 & 11,1400 & 17,9000 \\
ENDIV & 469 & 0,6224 & 0,2422 & 0,25000 & 1,1700 \\
LOGVPAP & 428 & 23,8666 & 0,8442 & 22,500 & 24,9000 \\
Q_TOBIN & 456 & 1,4586 & 0,6651 & 0,7962 & 2,9502 \\
AF & 469 & 1,5021 & 1,3432 & $-0,6000$ & 3,6000 \\
CRESC_VEND & 451 & 0,0473 & 0,1735 & $-0,2900$ & 0,3900 \\
ROE & 469 & 0,0716 & 0,1606 & $-0,2600$ & 0,3500 \\
LIQBOL & 473 & 0,1938 & 0,2660 & 0,0005 & 0,7702 \\
BETA & 376 & 0,8193 & 0,4500 & 0,1000 & 1,9400 \\
VOLAT & 358 & 37,1913 & 13,1830 & 22,8900 & 66,2800 \\
LOGVM & 468 & 21,0421 & 2,0592 & 16,3226 & 24,4323 \\
AO & 469 & 2,0045 & 1,9519 & $-1,4000$ & 5,8000 \\
\hline
\end{tabular}

Legenda: Q1 - questão 1 do ICA. Q2 - questão 2 do ICA. Q3 - questão 3 do ICA. Q4 - questão 4 do ICA. Q5 - questão 5 do ICA. Q6 - questão 6 do ICA. NGOV - nível de governança. ROA - retorno sobre o ativo. ICA - índice proposto para mensurar características dos conselhos de administração. LNAT - logaritmo natural do ativo total. ENDIV - exigível total /ativo total. LOGVPAP - logaritmo do índice valor patrimonial por ação/preço. Q TOBIN - valor de mercado das ações, somado ao valor das dívidas, dividido pelo ativo total. AF - alavancagem financeira. CRESC_VEND - variação percentual da receita operacional líquida de um ano para o outro. ROE - retorno sobre o patrimônio líquido. LIQBOL volume relativo de negociações com a ação. BETA - regressão do retorno mensal do título, contra o retorno mensal do Ibovespa, considerando os 60 meses anteriores. VOLAT - logaritmo do entre o valor de fechamento da ação pelo valor do dia anterior. LOGVM - logaritmo do valor da firma. AO - alavancagem operacional.

Fonte: resultados da pesquisa

$\mathrm{Na}$ análise descritiva da Tabela 4, o ICA, índice proposto neste estudo apresentou uma média de 2,3072, o que indica uma baixa adesão às recomendações do IBGC, quanto à composição dos conselhos de administração, dado que o valor máximo é 6 . 
Tabela 5

Teste de diferença de médias entre as variáveis dependentes e as questões sobre o Conselho

\begin{tabular}{|c|c|c|c|c|c|c|c|c|c|c|c|}
\hline \multicolumn{3}{|c|}{ ROA } & \multicolumn{3}{|c|}{ Q de Tobin } & \multicolumn{3}{|c|}{ Beta } & \multicolumn{3}{|c|}{ Volatilidade } \\
\hline Grupo & Obs & Média & Grupo & Obs & Média & Grupo & Obs & Média & Grupo & Obs & Média \\
\hline Q1 & & & Q1 & & & Q1 & & & Q1 & & \\
\hline 0 & 92 & 0,0110 & 0 & 87 & 1,5121 & 0 & 80 & 0,9038 & 0 & 55 & 40,5449 \\
\hline 1 & 331 & 0,257 & 1 & 326 & 1,4466 & 1 & 260 & 0,7830 & 1 & 270 & 36,1040 \\
\hline Q2 & & & Q2 & & & Q2 & & & Q2 & & \\
\hline 0 & 172 & 0,0226 & 0 & 168 & 1,4227 & 0 & 137 & 0,7245 & 0 & 111 & 38,1231 \\
\hline 1 & 191 & 0,0323 & 1 & 185 & 1,5120 & 1 & 149 & 0,8734 & 1 & 174 & 35,7453 \\
\hline Q3 & & & Q3 & & & Q3 & & & Q3 & & \\
\hline 0 & 17 & 0,0024 & 0 & 17 & 1,2921 & 0 & 14 & 0,5521 & 0 & 7 & 27,9943 \\
\hline 1 & 150 & 0,0243 & 1 & 147 & 1,4126 & 1 & 99 & 0,9884 & 1 & 133 & 36,2243 \\
\hline Q4 & & & Q4 & & & Q4 & & & Q4 & & \\
\hline 0 & 63 & 0,0154 & 0 & 63 & 1,3533 & 0 & 49 & 0,7731 & 0 & 45 & 34,4258 \\
\hline 1 & 180 & 0,0261 & 1 & 177 & 1,4747 & 1 & 137 & 0,9004 & 1 & 147 & 36,6799 \\
\hline Q5 & & & Q5 & & & Q5 & & & Q5 & & \\
\hline 0 & 207 & 0,0244 & 0 & 204 & 1,4033 & 0 & 158 & 0,8383 & 0 & 162 & 36,1217 \\
\hline 1 & 86 & 0,0094 & 1 & 85 & 1,3989 & 1 & 70 & 0,9214 & 1 & 70 & 39,9961 \\
\hline Q6 & & & Q6 & & & Q6 & & & Q6 & & \\
\hline 0 & 316 & 0,0226 & 0 & 308 & 1,4861 & 0 & 237 & 0,8591 & 0 & 243 & 37,3468 \\
\hline 1 & 121 & 0,0255 & 1 & 121 & 1,3004 & 1 & 112 & 0,7221 & 1 & 98 & 35,0803 \\
\hline
\end{tabular}

Fonte: resultados da pesquisa

Os testes de diferenças de médias mostraram a relação entre as respostas do questionário adaptado e as variáveis dependentes de desempenho/valor/risco. Entre as relações mostradas na Tabela 5, destacam-se as respostas da terceira questão, que mostraram maior diferença entre as respostas, e também entre as observações de cada pergunta. Esta questão, que foi adaptada do questionário original, conforme já mencionado anteriormente, mostrou que empresas com mais de $20 \%$ de membros externos possui maior associação com as variáveis valor/desempenho/risco do que empresas com menor número de conselheiros externos em seu conselho.

$\mathrm{Na}$ análise de correlação entre as variáveis, observa-se que existe baixa correlação entre elas, conforme apresentado na Tabela 6, com exceção das variáveis LOGVM e LNAT, que apresentam correlação maior que $0,8(0,8548)$, porém não figura como um problema para os modelos utilizados, uma vez que não estão juntas em um mesmo modelo. 


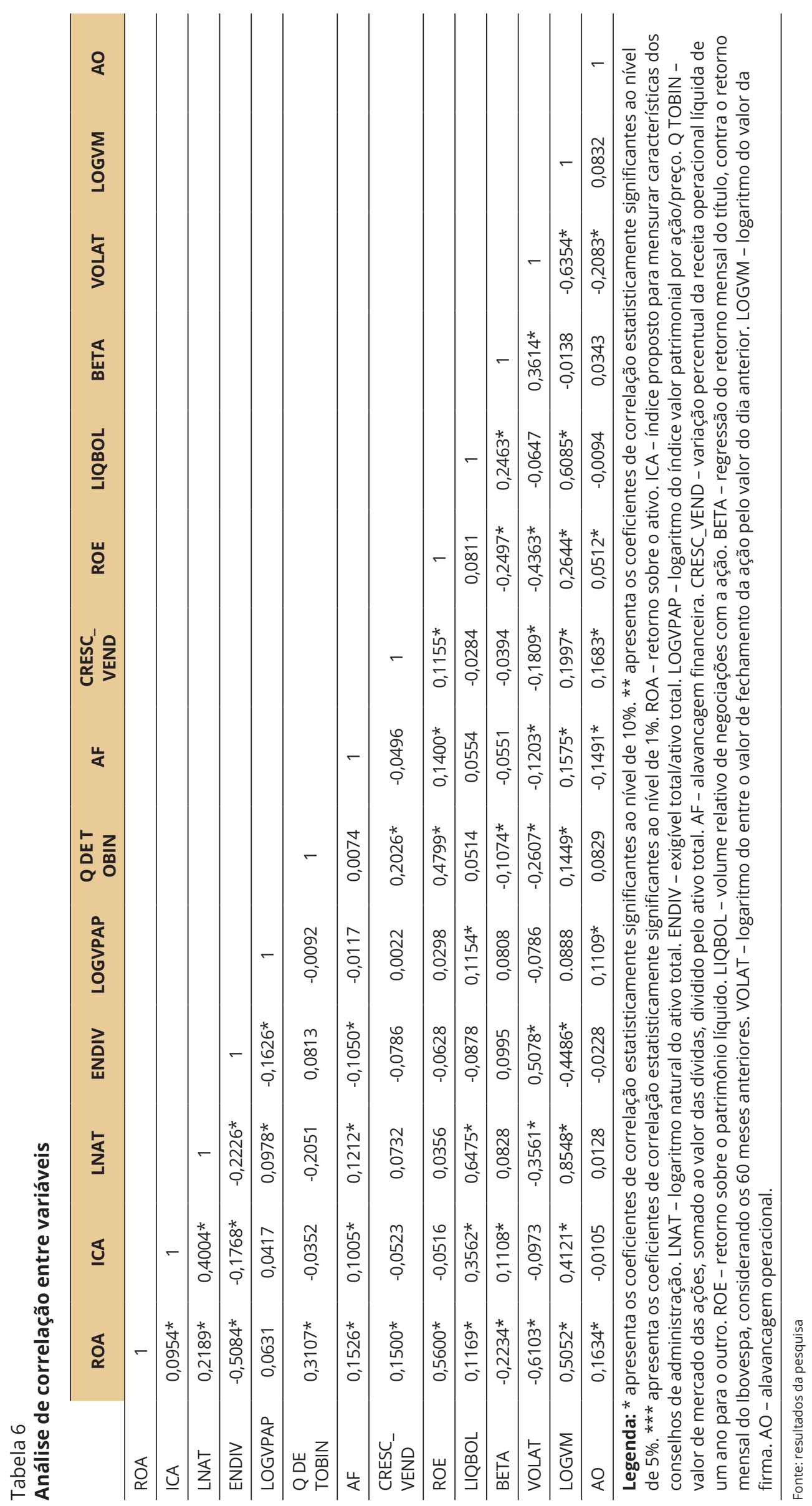




\section{Resultados das regressões}

O Teste de Hausman revelou ser o modelo de efeitos fixos o mais adequado para os três primeiros modelos (ROA, Q de Tobin e BETA). Já quando é utilizado a VOLAT como variável dependente o modelo de efeitos aleatórios, mostrou-se mais adequado.

Em suma, os resultados identificaram relação positiva do índice de conselho de administração (ICA) proposto neste estudo com a variável de risco VOLAT, diferente do que era esperado, e como foi encontrado por Lameira (2012), e de forma semelhante ao encontrado pelo índice proposto no estudo de Beiner et al. (2004), pois, com a adesão aos mecanismos de GC, espera-se que seja reduzido o risco dos investidores. As relações estatísticas apresentaram também significância entre as variáveis desempenho/ valor/risco com as variáveis de controle e também serão apresentadas a seguir.

As Tabelas 7 e 8 apresentam os resultados das regressões dos modelos propostos neste estudo. A Tabela 7 corresponde às regressões das variáveis dependentes ROA, objetivando medir o desempenho, e também à variável $\mathrm{Q}$ de Tobin para mensurar o valor. A Tabela 8 apresenta as relações entre as variáveis dependentes Beta e Volatilidade, ambas para medir o risco.

Tabela 7

Análise da relação entre as variáveis dependentes ROA e Q de Tobin e o Conselho de Administração

\begin{tabular}{ccc|ccc}
\hline ROA & Coeficiente & $\mathbf{P}>|\mathbf{t}|$ & Q_TOBIN & Coeficiente & $\mathbf{P}>|\mathbf{t}|$ \\
\hline ICA & $* 0,0021$ & $0,441^{* * * *}$ & ICA & $-0,0226$ & $0,283^{* * *}$ \\
\hline LNAT & $* 0,0395$ & $0,004^{* * * *}$ & LNAT & $-0,4091$ & $0,001 * * *$ \\
\hline ENDIV & $-0,2080$ & $0,0000^{* * *}$ & ENDIV & $-0,2937$ & $0,0401^{* *}$ \\
\hline LOGVPAP & $* 0,0011$ & $0,731 * * * *$ & AF & 0,0062 & $0,518^{* * *}$ \\
\hline NGOV & $* \star * * * * 0$ & (omitida) & CRESC_VEND & 0,2172 & $0,03^{* * * *}$ \\
\hline \multirow{2}{*}{} & & ROE & 0,4215 & $0,001^{* * *}$ \\
\cline { 3 - 5 } & & & LIQBOL & $-0,0882$ & $0,484^{* * * *}$ \\
\cline { 3 - 5 } & & & NGOV & 0 & (omitida)
\end{tabular}

Legenda: ROA - retorno sobre o ativo. ICA - índice proposto para mensurar características dos conselhos de administração. LNAT - logaritmo natural do ativo total. ENDIV - exigível total / ativo total. LOGVPAP - logaritmo do índice valor patrimonial por ação/preço. Q TOBIN - valor de mercado das ações, somado ao valor das dívidas, dividido pelo ativo total. AF - alavancagem financeira. CRESC_VEND - variação percentual da receita operacional líquida de um ano para o outro. ROE - retorno sobre o patrimônio líquido. LIQBOL - volume relativo de negociações com a ação. BETA - regressão do retorno mensal do título, contra o retorno mensal do lbovespa, considerando os 60 meses anteriores. VOLAT - logaritmo do entre o valor de fechamento da ação pelo valor do dia anterior. LOGVM - logaritmo do valor da firma. AO - alavancagem operacional.

Fonte: resultados da pesquisa

Na regressão do modelo com a variável dependente ROA, duas variáveis apresentaram significância. O logaritmo natural do ativo (LNAT) apresentou relação positiva com o ROA ao nível de 1\%, indicando que empresas maiores apresentam maior desempenho, e a variável Endividamento (ENDIV) apresentou associação negativa também ao nível de $1 \%$, indicando neste caso, que quanto maior o endividamento da empresa menor será o seu desempenho.

Os resultados corroboram os encontrados pelos autores Andrade et al. (2009), em que empresas já estabelecidas no mercado, ou seja empresas maiores em termos de ativos, são vistas como alvos preferenciais de investimento. Lameira et al. (2010) citaram também como possível justificativa o poder de negociação de empresas maiores perante os fornecedores, como forma de manter seu valor no mercado. No caso da variável endividamento, esperava-se relação negativa, conforme mencionaram Andrade et al. (2009), em que empresas com maior participação de capital de terceiros são vistas como de maior risco, inclusive pelo fato de terceiros exigirem, em alguns casos contratualmente, o direito de participar de decisões de investimento dentro da empresa. 
Os resultados do modelo econométrico referentes ao valor da empresa apresentaram associação positiva e significante entre o crescimento das vendas (CRESC_VEND) e o valor ao nível de 5\%, ou seja, infere-se com estes resultados que quanto maior for o crescimento das vendas, maior será o seu valor; de forma similar, ocorreu com o retorno sobre o patrimônio líquido (ROE), que apresentou significância ao nível de $1 \%$, indicando que quanto maior o retorno, maior será o valor da empresa.

Para a variável LNAT, o resultado apontou para uma relação negativa, ou seja, quanto maior o tamanho da empresa, menor será o seu valor. Esperava-se que quanto maior a firma, maior seria seu valor de mercado, conforme Lameira et al. (2010). Porém, o resultado encontrado não corroborou a literatura. Lameira et al. (2010) concluíram também em seu estudo que este resultado seria porque o mercado visualiza maior potencial de valor e de ganhos em empresas que ainda não estejam consolidadas ou maduras. Adicionalmente, os autores comentaram que empresas maiores conseguem oferecer melhores retornos, se conseguirem captar recursos mais baratos, enquanto que empresas menores conseguem aumentar seu valor mais rapidamente, com a adoção de melhores práticas de gestão.

Tabela 8

Análise da relação entre as variáveis dependentes Beta e Volatilidade e Conselho de Administração

\begin{tabular}{|c|c|c|c|c|c|}
\hline BETA & Coeficiente & $P>|t|$ & VOLAT & Coeficiente & $P>|z|$ \\
\hline ICA & 0,0039 & 0,9310 & ICA & 0,7448 & $0,099 *$ \\
\hline VOLAT & 0,0134 & $0,001 * * *$ & BETA & 7,8662 & $0,0000 * * *$ \\
\hline LOGVPAP & $-0,0460$ & 0,1470 & LOGVPAP & $-0,5565$ & 0,365 \\
\hline LOGVM & 0,2385 & $0,006 * \star \star$ & LOGVM & $-5,7046$ & $0,0000 * * *$ \\
\hline LIQBOL & $-0,6034$ & $0,002 * * *$ & LIQBOL & 17,5990 & $0,0000 * * *$ \\
\hline $\mathrm{AO}$ & 0,0162 & 0,3450 & $\mathrm{AO}$ & $-0,7123$ & $0,01 * *$ \\
\hline $\mathrm{AF}$ & $-0,0015$ & 0,9410 & $\mathrm{AF}$ & 0,0211 & 0,0958 \\
\hline CRESC_VEND & 0,0173 & 0,8900 & CRESC_VEN & 4,3344 & 0,164 \\
\hline NGOV & 0 & (omitida) & NGOV & $-4,9158$ & $0,000 * * *$ \\
\hline
\end{tabular}

Legenda: ROA - retorno sobre o ativo. ICA - índice proposto para mensurar características dos conselhos de administração. LNAT - logaritmo natural do ativo total. ENDIV - exigível total/ativo total. LOGVPAP - logaritmo do índice valor patrimonial por ação/preço. Q TOBIN - valor de mercado das ações, somado ao valor das dívidas, dividido pelo ativo total. AF - alavancagem financeira. CRESC_VEND - variação percentual da receita operacional líquida de um ano para o outro. ROE - retorno sobre o patrimônio líquido. LIQBOL - volume relativo de negociações com a ação. BETA - regressão do retorno mensal do título, contra o retorno mensal do lbovespa, considerando os 60 meses anteriores. VOLAT - logaritmo do entre o valor de fechamento da ação pelo valor do dia anterior. LOGVM - logaritmo do valor da firma. AO - alavancagem operacional.

Fonte: resultados da pesquisa

As regressões entre as variáveis dependentes BETA e VOLAT, com o índice conselho de administração (ICA), buscaram identificar uma possível relação entre ter um conselho que atenda às recomendações do IBGC, e reduções no risco sistemático e no risco total da firma, respectivamente. Seus resultados foram apresentados na Tabela 8 e interpretados a seguir.

No que tange ao modelo cuja variável dependente foi o Beta, a variável volatilidade (VOLAT) e tamanho da firma (LOGVM) apresentaram relação positiva e significante com o risco sistemático. Da primeira relação, infere-se que quanto maior a volatilidade das ações da empresa no mercado, maior será seu risco sistemático. Da mesma forma, quanto maior o LOGVM, que neste caso é uma proxy para tamanho da firma, maior será o risco do investidor, corroborando neste caso o estudo de Peixoto (2012). Por sua vez, a variável liquidez das ações em bolsa de valores (LIQBOL) mostrou relação negativa e significante com o beta, indicando que quanto maior o volume de negociações das ações da empresa na bolsa, menor será o seu risco. 
O modelo cuja variável dependente foi a VOLAT, obteve relação positiva e significante ao nível de 10\% entre o índice proposto, o ICA, e a variável dependente, e também relações positivas e negativas com as variáveis de controle. As variáveis BETA e LIQBOL se enquadram no primeiro grupo, e as variáveis LOGVM, AO e NGOV, no segundo.

No caso do índice proposto, quanto mais abrangente for a adesão da empresa as recomendações do IBGC, quanto ao mecanismo de conselho de administração, maior será sua volatilidade. O esperado pela literatura era o contrário, já que o mecanismo tem entre seus objetivos reduzir o risco das ações da empresa para os investidores, conforme encontrado por Lameira (2012). Para o primeiro grupo, infere-se, pela regressão, que quanto maior o Beta da empresa maior será a volatilidade das ações no mercado, e que quanto maior a liquidez da empresa na bolsa de valores, maior será sua volatilidade.

Para o segundo grupo, infere-se que quanto maior o valor de mercado da empresa, menor será a volatilidade das ações; quanto maior a alavancagem operacional da empresa, menor será a volatilidade, ou variação das ações no mercado e pertencer aos níveis diferenciados de GC da bolsa reduz a volatilidade das ações da firma.

\section{Considerações Finais}

Este estudo teve como objetivo principal verificar a influência de um dos mecanismos de GC, o conselho de administração, sobre o desempenho/valor/risco de empresas brasileiras de capital aberto, nos anos de 2012 e 2013. Para isso, inicialmente foi construído um índice de conselho de administração. Este índice foi denominado de ICA e usou como base as respostas de um questionário com 6 perguntas binárias adaptadas do estudo de Silva et al. (2011). Após a criação do ICA, buscou-se relacionar as variáveis de interesse por meio de modelos de regressão com dados em painel, utilizando predominantemente o modelo de efeitos fixos.

Esperava-se que os resultados encontrados indicassem relação positiva deste mecanismo com as variáveis dependentes "valor e desempenho" e "negativa com o risco", mostrando a importância de se adotar as recomendações do IBGC ao estruturar um conselho de administração, de forma semelhante ao encontrado no estudo de Beiner et al. (2004), em que foi proposto um índice de GC para empresas suíças. No entanto, o ICA apresentou relação positiva com a variável VOLAT, diferente do encontrado por Lameira (2012). Desta forma, conclui-se que a adoção do conselho de administração, não reduziria o risco aos acionistas.

O resultado desta pesquisa sobre o efeito do conselho de administração sobre o desempenho e valor das empresas encontra semelhanças com outros estudos internacionais, como o de Shakir (2008), que encontrou resultados inconclusivos sobre a composição dos conselhos no desempenho de empresas na Malásia, bem como o estudo de Velnampy (2013), que não encontrou relação entre GC e desempenho, no Siri Lanka.

Foram encontradas relações significativas entre as variáveis dependentes e algumas de controle. A variável LNAT apresentou relação positiva com a variável ROA, conforme esperado, indicando que empresas maiores, ou seja, empresas mais consolidadas no mercado como apontam Andrade et al. (2009), apresentam melhor desempenho. Ao contrário, a variável ENDIV apresentou relação negativa com a variável de desempenho, corroborando como Andrade et al. (2009) e Silva et al. (2011). O endividamento pode ser interpretado como uma possível interferência de credores no planejamento estratégico da empresa, visando apenas o retorno sobre o valor investido, sem alinhamento com o interesse de maximização da riqueza dos acionistas e, portanto, influenciando no seu desempenho.

Na relação das variáveis com o Q de Tobin, diferentemente do esperado, a variável LNAT apresentou relação negativa com o valor. O crescimento das vendas mensurado pelo CRESC_VEND e o retorno sobre o patrimônio líquido, mensurado pelo ROE, apresentaram relação positiva, conforme esperado. Empresas com crescimento nas vendas apresentam melhor desempenho e, na maioria das vezes, melhores resultados financeiros e, consequentemente, podem oferecer maiores retornos aos acionistas. 
As variáveis dependentes de risco (o BETA e o VOLAT) apresentaram relação positiva, ora com o VOLAT, ora com o BETA, comprovando o que era esperado - o beta e a volatilidade das ações caminham juntos no mercado acionário. O valor de mercado mensurado por seu logaritmo natural apresentou relação positiva com o BETA, contrariando o resultado esperado, possivelmente indicando que empresas com maior valor de mercado possuem maior risco de desvalorização e perda do investimento para os acionistas. A variável LIQBOL apresentou relação negativa com o BETA. Infere-se desta relação que empresas com maior liquidez em bolsa, ou seja, mais procuradas para comercialização, possuem menor risco, o que está de acordo com o esperado.

No caso do modelo cuja variável dependente era a VOLAT, sua relação com a variável LIQBOL foi positiva, ao contrário da relação desta variável com o Beta, citada no parágrafo anterior. Esperava-se que esta relação fosse positiva, pois empresas mais negociadas possuem maior volatilidade. Por sua vez, as variáveis LOGVM, AO e NGOV apresentaram relações negativas com a volatilidade. O aumento do valor de mercado, assim como a alavancagem operacional, é reflexo de empresas já estabelecidas no mercado, que apresentaram evolução em indicadores de resultado, como receita bruta, margem operacional e lucro líquido. Desta forma, esperava-se que estas variáveis de controle apresentassem relação positiva com a volatilidade, por serem usadas por investidores para tomada de decisão de alocação de capital. Isto é, empresas com melhores resultados financeiros seriam mais procuradas no mercado de capitais. Por outro lado, infere-se neste estudo que pertencer aos níveis diferenciados de GC da bolsa pode reduzir a volatilidade das ações, o que era esperado, e como concluíram os autores Lameira et al. (2010).

Como sugestões para futuras pesquisas, recomenda-se estender o período de análise, a amostra e o número de questões do questionário sobre o conselho de administração, de forma a abranger um número maior de características desse importante mecanismo de governança corporativa.

\section{Referências}

Alchian, A. A., \& Demsetz, H. (1972). Production, information costs, and economic organization. The American Economic Review, 62(5), pp. 777-795. doi: 10 1257/era. 101.1.1

Andrade, L. P. D., Salazar, G. T., Calegário, C. L. L., \& Silva, S. S. (2009). Corporate governance: an analysis of board of directors in relation with the value of market and performance of the Brazilian companies. RAM. Revista de Administração Mackenzie, 10(4), pp. 4-31. doi: 10.1590/S 1678

Beiner, S., Drobetz, W., Schmid, M., \& Zimmermann, H. (2004). An Integrated Framework of Corporate Governance and Firm Valuation - Evidence from Switzerland. ECGI - Finance Working Paper, 34.

Berle, A. A., \& Means, G.C. (1932) The Modern Corporation and Private Property. Macmillan, New York.

Bhagat, S., \& Bolton, B. J. (2009). Sarbanes-Oxley, governance and performance. Available at SSRN 1361815 .

Carter, D. A., Simkins, B. J., \& Simpson, W. G. (2003). Corporate governance, board diversity, and firm value. Financial Review, 38(1), pp. 33-53. doi: 10.1111/1540-6288.00034

Carvalhal da Silva, A. L. (2004). Governança corporativa, valor, alavancagem e política de dividendos das empresas brasileiras. Revista de Administração da Universidade de São Paulo, 39(4)

Carvalhal da Silva, A. L., \& Leal, R. P. C. (2006). Ownership, control, valuation and performance of Brazilian corporations. Corporate Ownership \& Control, 4(1), pp. 300-308.

Chung, K. H., \& Pruitt, S. W. (1994). A simple approximation of Tobin's q. Financial management, 23(3), pp. $70-74$. DOI: $10.2307 / 3665623$

Coase, R. H. (1937). The nature of the firm. Economica, 4(16), pp. 386-405. DOI: 10.1111/j.14680335.1937.tb00002.x 
Coles, J. L., Daniel, N. D., \& Naveen, L. (2008). Boards: Does one size fit all? Journal of Financial Economics, 87(2), pp. 329-356. doi:10.1016/j.jfineco.2006.08.008

Fauver, L., \& Fuerst, M. E. (2006). Does good corporate governance include employee representation? Evidence from German corporate boards. Journal of Financial Economics, 82(3), pp. 673-710. doi:10.1016/j.jfineco.2005.10.005

Fraga, J. B., \& Silva; V. A. B. (2012) Diversidade no conselho de administração e desempenho da empresa: uma investigação empírica. BBR - Brazilian Business Review, (Edição Especial BBR Conference), pp. 58-80. DOI: http://dx.doi.org/10.15728/bbrconf.2012.3

Gondrige, E. O., Clemente, A., \& Espejo, M. M. D. S. B. (2012). Estrutura do conselho de administração e valor das companhias brasileiras. BBR-Brazilian Business Review, 9(3), pp. 72-95. DOI:http://dx.doi. org/10.15728/bbr.2012.9.3.4.

Guimarães, T. M.; Marques, T.A.; \& Peixoto, F. M. (2014, Julho) A Concentração Acionária no Brasil: Análise dos Impactos no Desempenho, Valor e Risco das Empresas. Encontro Brasileiro de Finanças, Recife, Pernambuco, Brasil, 14.

Hermalin, B. E., \& Weisbach, M. S. (2001). Boards of directors as an endogenously determined institution: A survey of the economic literature. National Bureau of Economic Research, Working Paper 8161.

Holtz, L., Vargas, L. H. F., Macedo, M. A. S., \& Bortolon, P. M. (2013). Análise do tamanho do conselho de administração: evidências no mercado brasileiro. Advances in Scientific and Applied Accounting, 6(3), pp. 321-347. Doi 10.14392/ASAA.2013060303

Instituto Brasileiro de Governança Corporativa - IBGC. Recuperado em 23 Agosto, 2014 de www.ibgc.org.br

Jensen, M. C. \& Meckling, W. H. (1976). Theory of the firm: Managerial behavior, agency costs, and ownership structure. Journal of Financial Economics. (3)4, pp. 305-360. http://dx.doi.org/10.2139/ssrn.94043

Joecks, J., Pull, K., \& Vetter, K. (2013). Gender diversity in the boardroom and firm performance: What exactly constitutes a "critical mass?". Journal of business ethics, 118(1), pp. 61-72, doi: 10.1007/ s10551-012-1553-6.

Kumar, N., \& Singh, J. P. (2012). Outside directors, corporate governance and firm performance: Empirical evidence from India. Asian Journal of Finance \& Accounting, 4(2), pp. 39-55, doi: http://dx.doi. org/10.5296/ajfa.v4i2.1737

Lameira, V. J. (2007) Governança Corporativa, risco e desempenho das companhias abertas brasileiras uma análise do relacionamento entre as práticas de Governança Corporativa, o risco e o desempenho das companhias abertas brasileiras. Tese de Doutorado, Pontifícia Universidade Católica do Rio de Janeiro (PUC-Rio), Rio de Janeiro, RJ, Brasil. Recuperado de http://www.maxwell.vrac.puc-rio. br/11174/11174_1.PDF

(2012). As Relações entre Governança e Risco nas Companhias Abertas Brasileiras. Revista Brasileira de Gestão de Negócios, 14(42), pp. 7-25. Doi:10.7819/rbgn.v14i42.871

Lameira, V. D. J., Júnior, W. L. N., da Silva, P. P., da Motta, L. F. J., \& Klötzle, M. C. (2010). Governança, risco e desempenho das companhias abertas brasileiras. Revista de Economia e Administração, 9(1).

Lipton, M., \& Lorsch, J. W. (1992). A modest proposal for improved corporate governance. The business lawyer, pp. 59-77. Doi: 10.12691/jfa-2-4-2

Peixoto, F. M. (2012). Governança corporativa, desempenho, valor e risco: estudo das mudanças em momentos de crise. 2012. Tese de Doutorado, Universidade Federal de Minas Gerais, Belo Horizonte, MG, Brasil. Recuperado de http://cepead.face.ufmg.br/btd/files/360/a360t2

Rodrigues, A. T. L. (2003, Agosto). Governança Corporativa: Quando a transparência passa a ser uma exigência global. Convenção de Contabilidade do Rio Grande do Sul. Gramado, RS, Brasil, 9. 
Santos, J. F. \& Leal, R. P. C. (2007) Práticas de Governança Corporativa em empresas familiares não-listadas de capital aberto. Anais do Encontro Brasileiro de Finanças, São Paulo, SP, Brasil, 7.

Silva, E. S., Santos, J. F., \& Almeida, M. A. (2011). Conselho de Administração: uma análise da influência nos níveis de endividamento. Revista Brasileira de Gestão de Negócios, 13(41), pp. 440-453, Recuperado de http://www.redalyc.org/articulo.oa?id=94722337005. Doi: 10.7819/rbgn.v13i41.835

Silveira, A. D. M. (2002). Governança corporativa, desempenho e valor da empresa no Brasil, Dissertação de Mestrado, Universidade de São Paulo, São Paulo, SP, Brasil. Recuperado de http://www.teses. usp.br/teses/disponiveis/12/12139/tde-04122002-102056/en.php

Silveira, A. D. M., Barros, L. A. B. C., \& Famá, R. (2003). Estrutura de governança e valor das companhias abertas brasileiras. RAE-Revista de Administração de Empresas, 43(3), pp. 50-64. http://dx.doi. org/10.1590/S0034-75902003000300005

Shakir, R. (2008). Board size, executive directors and property firm performance in Malaysia. Pacific Rim Property Research Journal, 14(1), pp. 66-68.

Shleifer, A., \& Vishny, R. W. (1997). A survey of corporate governance. The journal of finance, 52(2), pp. 737-783. doi:10.1111/j.1540-6261.1997.tb04820.x

Velnampy, T. (2013). Corporate governance and firm performance: a study of Sri Lankan manufacturing companies. Journal of Economics and Sustainable Development, 4(3), pp. 228-235.

Williamson, O. E. (1985) The Economic Institution of Capitalism. New York: The Free Press. 